\title{
Study of ectopic pregnancy in a tertiary care centre
}

\author{
Dhirajkumar B. Shukla*, Sunil V. Jagtap, Pradnya P. Kale, Hardik N. Thakkar
}

Department of Pathology, Krishna Institute of Medical Sciences, Karad, Maharashtra, India

Received: 24 December 2016

Revised: 27 December 2016

Accepted: 31 January 2017

\section{*Correspondence:}

Dr. Dhirajkumar B. Shukla,

E-mail: drshukla.patho@gmail.com

Copyright: (C) the author(s), publisher and licensee Medip Academy. This is an open-access article distributed under the terms of the Creative Commons Attribution Non-Commercial License, which permits unrestricted non-commercial use, distribution, and reproduction in any medium, provided the original work is properly cited.

\begin{abstract}
Background: Ectopic pregnancy is a life threatening emergency leading to maternal death. Incidence of ectopic pregnancies has been increasing in last two to three decades with reduction in mortality. The presenting symptoms include abdominal pain, amenorrhoea and/or irregular vaginal bleeding. The present study was undertaken to study the clinical features of ectopic pregnancies in a tertiary care hospital.

Methods: The present study on ectopic pregnancies was carried out in Department of Pathology, Krishna Institute of Medical Sciences, Karad, Maharashtra, India from January 2010 to June 2014. All the cases of ectopic pregnancy managed surgically were included in the study.

Results: Total 102 cases of ectopic pregnancy were studied. Proportion of ectopic pregnancy in the present study is 1 in 205 deliveries. Majority of the cases (37) (36.27\%) were noted between 21 to 25 years of age group followed by the age group 26 to 30 years. Ectopic pregnancy was most commonly noted in nulliparous women (44/102) (43.14\%). Majority of the cases (50/102) $(49.02 \%)$ had no risk factors. Abortion was the most common risk factor identified, alone as well as in conjunction with other factors. Ampulla was the most common site for ectopic pregnancy. 55\% of the cases were on the right side where as $45 \%$ on the left side. We had 2 cases of heterotropic pregnancy with tubal ectopic in both the cases. The typical triad of amenorrhoea, pain in abdomen and bleeding was observed in $21.57 \%$ cases.

Conclusions: The incidence of ectopic pregnancies is on rise as evident in this study. In order to reduce the morbidity and mortality due to ectopic pregnancies, there is need for early diagnosis especially in high risk cases.
\end{abstract}

Keywords: Ampulla, Ectopic pregnancy, Pain in abdomen, Rudimentary horn

\section{INTRODUCTION}

Ectopic pregnancy is a life threatening emergency leading to maternal death. Several risk factors have been identified for ectopic pregnancies viz. pelvic inflammatory disease, previous pelvic surgery, previous ectopic pregnancy, intrauterine device usage, induction of ovulation, smoking etc. Incidence of ectopic pregnancies has been increasing in last two to three decades with reduction in mortality. This can be attributed to the advent of newer and better diagnostic techniques and early diagnosis.
Ectopic pregnancy includes all gestations when fertilized ovum is implanted in: ${ }^{1}$

- Fallopian tube

a. Interstitial portion

b. Isthmus

c. Ampulla (most common)

d. Infundibulum

- Ovarian pregnancy

- Cervical pregnancy

- Pregnancy in a rudimentary uterine horn

- Primary abdominal pregnancy 
- Caesarian scar pregnancy

Classically, the presenting symptoms include abdominal pain, amenorrhoea and/or irregular vaginal bleeding. Multiple parameters used for the diagnosis of ectopic pregnancy are ultrasonography, urinary pregnancy test, $\beta$ hCG levels and several other biomarkers.

Cases of ectopic pregnancies can be managed conservatively or surgically depending on the condition of the patient. Medical management is by administration of methotrexate and surgically these cases are managed either by salpingectomy (most common) or salphingooopherectomy or hysterectomy (rarely). The present study was undertaken to study the clinical features of ectopic pregnancies in a tertiary care hospital.

\section{METHODS}

The present study on ectopic pregnancies was carried out in Department of Pathology, Krishna Institute of Medical Sciences, Karad, Maharashtra, India from January 2010 to June 2014. All the cases of ectopic pregnancy managed surgically were included in the study. All the cases of ectopic pregnancy with medical management were excluded from the study. Clinical details were noted in a predefined proforma.

\section{RESULTS}

Total 20845 patients delivered during the period of 4 and $1 / 2$ years from January 2010 to June 2014. Total 143 cases of ectopic pregnancy were noted, out of which 102 cases were surgically treated and remaining were managed medically. 102 cases which were managed surgically were included in this study. Proportion of ectopic pregnancy in the present study is 1 in 205 deliveries. Majority of the cases $(n=37)(36.27 \%)$ were noted between 21 to 25 years of age group followed by the age group 26 to 30 years. Youngest case was a 19 years old female and oldest was a 42 year old lady (Table 1).

Table 1: Cases of ectopic pregnancy in relation to age.

\begin{tabular}{|ll|l|}
\hline Age group (years) & No. of cases & Percentage \\
\hline $15-20$ & 2 & $1.96 \%$ \\
\hline $21-25$ & 37 & $36.27 \%$ \\
\hline $26-30$ & 31 & $30.4 \%$ \\
\hline $31-35$ & 20 & $19.61 \%$ \\
\hline $36-40$ & 11 & $10.78 \%$ \\
\hline $41-45$ & 1 & $0.98 \%$ \\
\hline Total & 102 & $100 \%$ \\
\hline
\end{tabular}

Ectopic pregnancy was most commonly noted in nulliparous women $(43.14 \%)$. It can be noted that the incidence of ectopic pregnancy goes down with increasing parity (Table 2). With the increasing age, the parity also increased linearly.
Table 2: Distribution of cases based on parity.

\begin{tabular}{|lll|}
\hline Parity & No. of cases & Percentage \\
\hline Nulliparous & 44 & $43.14 \%$ \\
\hline 1 & 29 & $28.43 \%$ \\
\hline 2 & 22 & $21.57 \%$ \\
\hline 3 & 4 & $3.92 \%$ \\
\hline 4 & 3 & $2.94 \%$ \\
\hline Total & 102 & 100.0 \\
\hline
\end{tabular}

Table 3: Distribution of cases based on the site of ectopic pregnancy.

\begin{tabular}{|lll|}
\hline Site of ectopic pregnancy & No. of cases & Percentage \\
\hline Ampullary & 64 & $62.74 \%$ \\
\hline Isthmal & 27 & $26.48 \%$ \\
\hline Fimbrial & 3 & $2.94 \%$ \\
\hline Cornual & 3 & $2.94 \%$ \\
\hline Ovary & 2 & $1.96 \%$ \\
\hline Rudimentary horn & 3 & $2.94 \%$ \\
\hline Total & 102 & $100 \%$ \\
\hline
\end{tabular}

\section{Risk factors}

Majority of the cases $(n=50)(49.02 \%)$ had no risk factors. Abortion was the most common risk factor identified. Only abortion was noted in $12.75 \%$ of cases whereas abortion along with other risk factors like tubal surgery $(3.92 \%)$, appendicectomy $(2.94 \%)$, infertility $(1.96 \%)$, Intrauterine device $(1.96 \%)$, PID and endometriosis $(0.98 \%)$ was also noted. Tubal surgery alone was noted in $11.76 \%$ of the cases. History of pelvic surgery, pelvic inflammatory disease, infertility and previous ectopic pregnancy was noted in $1.96 \%$ of the cases each. $3(2.94 \%)$ cases showed the presence of congenital anomaly in the uterus. Pelvic surgery done were appendicectomy and lower section caesarian section (LSCS) was noted in 1 case each. History of in vitro fertilization was noted in a single case.

Table 4: Clinical presentation.

\begin{tabular}{|lll|}
\hline Symptoms & No. of cases & Percentage \\
\hline Amenorrhea & 56 & $54.90 \%$ \\
\hline Pain abdomen & 70 & $68.63 \%$ \\
\hline Bleeding & 32 & $31.37 \%$ \\
\hline Others & 13 & $12.75 \%$ \\
\hline
\end{tabular}

Table 5: Correlation of general examination findings and preoperative condition of the tube.

\begin{tabular}{|c|c|c|c|}
\hline \multirow{2}{*}{$\begin{array}{l}\text { Mode of } \\
\text { presentation }\end{array}$} & \multicolumn{3}{|c|}{ Condition of tube } \\
\hline & Ruptured & Tubal abortion & Unruptured \\
\hline Pallor & 54 & 2 & 20 \\
\hline Shock & 4 & 0 & 0 \\
\hline None & 8 & 1 & 12 \\
\hline Total & 62 & 3 & 32 \\
\hline
\end{tabular}




\section{Site}

Ampulla was the most common site for ectopic pregnancy. $55 \%$ of the cases were on the right side where as $45 \%$ on the left side. We had 2 cases of heterotropic pregnancy with tubal ectopic in both the cases (Table 3 ).

Table 6: Distribution of the cases based on the surgical procedure done.

\begin{tabular}{|lll|}
\hline Procedure & $\begin{array}{l}\text { No. of } \\
\text { cases }\end{array}$ & Percentage \\
\hline Unilateral salpingectomy & 54 & $52.94 \%$ \\
\hline Bilateral salpingectomy & 11 & $10.78 \%$ \\
\hline $\begin{array}{l}\text { Unilateral salpingo- } \\
\text { oophorectomy }\end{array}$ & 21 & $20.59 \%$ \\
\hline $\begin{array}{l}\text { Salpingo-oophorectomy with } \\
\text { contra lateral tubectomy }\end{array}$ & 3 & $2.94 \%$ \\
\hline Segmental isthmic resection & 8 & $7.84 \%$ \\
\hline Cornual resection & 5 & $4.91 \%$ \\
\hline Total & 102 & $100 \%$ \\
\hline
\end{tabular}

\section{Clinical presentation}

The typical triad of amenorrhoea, pain in abdomen and bleeding was observed in $21.57 \%$ cases. Abdominal pain was the most significant symptom in $68.63 \%$ of patients. Other symptoms were giddiness, nausea and vomiting, syncopal attacks seen in $12.75 \%$ cases (Table 4). Abdominal pain and amenorrhoea were the most common symptoms in patients who had ampullary pregnancy.

Table 7: Distribution of the cases on the basis of the condition of the fallopian tube.

\begin{tabular}{|lll|}
\hline Condition of the tube & No. of cases & Percentage \\
\hline Ruptured & 62 & $63.92 \%$ \\
\hline Tubal abortion & 3 & $3.09 \%$ \\
\hline Unruptured & 32 & $32.99 \%$ \\
\hline Total & 97 & $100 \%$ \\
\hline
\end{tabular}

Patients who had a ruptured fallopian tube, had amenorrhoea and acute pain in abdomen as their major symptoms on admission, whereas $33.3 \%$ of the patients who had a tubal abortion, presented with other symptoms like nausea, vomitting and syncopal attacks. Patients with unruptured tubal pregnancies also had similar symptoms but only in smaller proportions.

Majority of the patients presented with pallor and ampulla as the most common site. Tube was ruptured in 54 patients who presented with pallor. 4 patients who were brought in shock had ruptured tubal pregnancy on laparotomy (Table 5).

Bleeding per vaginum on speculum examination was noted in $32(31.37 \%)$ patients.
Uterus was normal in size in $80.39 \%$ of the cases. Increased size was noted in $19.61 \%$ cases.

Urine pregnancy test was positive in $98.04 \%$ of the cases. Urine pregnancy test was negative only in 2 cases of tubal abortion.

Ultrasonography showed $61.77 \%$ of the cases had ruptured ectopic pregnancy.

Table 8: Correlation of the site of ectopic pregnancy and condition of the tube.

\begin{tabular}{|lllll|}
\hline $\begin{array}{l}\text { Site of } \\
\text { ectopic } \\
\text { pregnancy }\end{array}$ & Ruptured & $\begin{array}{l}\text { Tubal } \\
\text { abortion }\end{array}$ & $\begin{array}{l}\text { Un- } \\
\text { ruptured }\end{array}$ & Total \\
\hline Ampullary & 40 & 3 & 21 & 64 \\
\hline Isthmal & 19 & 0 & 8 & 27 \\
\hline Fimbrial & 2 & 0 & 1 & 3 \\
\hline Cornual & 1 & 0 & 2 & 3 \\
\hline Total & 62 & 3 & 32 & 97 \\
\hline
\end{tabular}

Significantly more cases underwent unilateral salpingectomy $(52.94 \%)$, followed by unilateral salpingooophorectomy. $\quad 10.78 \%$ underwent bilateral salpingectomy as they had completed their families (Table 6). Cornual resection was performed in all the cases of rudimentary horn pregnancy and in 2 cases of cornual pregnancy. Both the cases of heterotropic pregnancy underwent unilateral salpingectomy and intrauterine pregnancy was continued. Of the 2 cases of heterotropic pregnancy one delivered a healthy male child while other had spontaneous miscarriage.

Ruptured fallopian tube was noted in $63.92 \%$ of the tubal ectopic pregnancy cases; while $32.99 \%$ showed intact tube and $3.09 \%$ had tubal abortion (Table 7). In this study, among the 62 cases of ampullary pregnancy, 40 patients had a ruptured tube and 3 cases, had tubal abortion. 19 cases of the isthmal ectopic culminated in tubal rupture. $66.6 \%$ of fimbrial ectopic ended in tubal rupture (Table 8 ).

\section{DISCUSSION}

\section{Incidence}

The incidence of ectopic pregnancy is increasing with decrease in the mortality and morbidity. The increased incidence is attributed to the early diagnosis owing to the advent of newer diagnostic techniques. Incidence reported by ICMR in their study was 1 in 250 deliveries. $^{2}$ Studies by Laxmi RC et al, Baria DD et al and Shraddha Shetty et al have shown increase in the incidence which was also observed in the present study. ${ }^{3-5}$ Present study showed an incidence of 1 in 205 deliveries which was in concordance with the studies of ICMR and Shraddha Shetty et al. ${ }^{2,5}$ 
Table 9: Correlation of studies on ectopic pregnancy in relation to age.

\begin{tabular}{|c|c|c|c|c|}
\hline Age groups in years & Sanjay $\mathbf{P}$ et $\mathbf{a l}^{6}$ & Shivakumar $\mathrm{HC}$ et $\mathrm{al}^{7}$ & Singh $\mathrm{S}$ et $\mathrm{al}^{8}$ & Present study \\
\hline $15-20$ & $5 \%$ & $10 \%$ & $0 \%$ & $1.96 \%$ \\
\hline $21-25$ & $47.5 \%$ & $32.5 \%$ & $44 \%$ & $36.27 \%$ \\
\hline $26-30$ & $25 \%$ & $37.5 \%$ & $36 \%$ & $30.4 \%$ \\
\hline $31-35$ & $20 \%$ & $10 \%$ & $16 \%$ & $19.61 \%$ \\
\hline $36-40$ & $2.5 \%$ & $5 \%$ & $4 \%$ & $10.78 \%$ \\
\hline $41-45$ & $0 \%$ & $5 \%$ & $0 \%$ & $0.98 \%$ \\
\hline
\end{tabular}

Age

In the present study maximum cases belonged to the age group 21-25 years, which is in agreement with other studies (Table 9).

Some authors have reported 26-30 years of age as the most common age group. Overall study shows that maximum numbers of cases are noted in the third decade of life.

\section{Parity}

In the present study, the maximum incidence of ectopic pregnancies occurred between, parity 0 and 2 . But in the study by Panchal et al and Singh et al, as parity increases there is a decrease in the incidence of ectopic pregnancy. ${ }^{8,9}$ According to ICMR multicentric case control study of ectopic pregnancy, majority of women were young and had low parity. Present study also showed similar results. ${ }^{2}$

\section{Risk factors}

In the present study nearly half of the patient did not have any contributing risk factors. Among the cases with positive history of risk factors, abortion was the most common risk factor noted. This finding was in conjunction with the findings of Shivakumar $\mathrm{HC}$ et al and Baria DD et al. ${ }^{4,7}$

\section{Clinical symptoms}

Manifestations of an unruptured ectopic pregnancy are not characteristic. Correct diagnosis is rarely arrived at. Almost all the symptoms and signs produced by ectopic pregnancy are caused by ultimate rupture or abortion with resultant hemorrhage into the peritoneal cavity. Hence, symptoms and signs of ectopic pregnancy as described are nothing but the clinical description of ectopic gestation which has been disturbed.

In the present study, it was found that only $22(21.57 \%)$ cases of ectopic pregnancy presented with the classical presentation of amenorrhoea, bleeding per vaginum, fainting attacks, abdominal pain, tenderness and adnexal mass. No specific sign or symptom can be said to be pathognomonic of ectopic gestation, but combination of various findings may be suggestive.

The classical history of amenorrhoea, pain abdomen and vaginal bleeding was present only in $22(21.57 \%)$ cases. Presence of shock was seen only in 4 cases. The clinical picture is dependent on several factors, the most important factor being the extent of time taken for disturbance to occur in ectopic gestation. The more extensive and rapid the disturbance, the clearer is the clinical picture. Hence, undisturbed ectopic gestation is likely to be missed in majority of the cases as the clinical features are vague. Acute pain in the lower abdomen was the most common presenting feature in $70(68.63 \%)$ cases.

Table 10: Correlation studies of clinical presentation in cases of ectopic pregnancy.

\begin{tabular}{|c|c|c|c|c|}
\hline Clinical presentation & Gaddagi $R$ et $a^{10}$ & Shabab U et al ${ }^{11}$ & Shetty $\mathrm{S}$ et $\mathrm{al}^{5}$ & Present study \\
\hline Amenorrhea & $75.7 \%$ & $75 \%$ & $77.4 \%$ & $54.90 \%$ \\
\hline Pain abdomen & $89.2 \%$ & $92.5 \%$ & $80.6 \%$ & $68.63 \%$ \\
\hline Bleeding & $43.2 \%$ & $45 \%$ & $61.3 \%$ & $31.37 \%$ \\
\hline Others & $0 \%$ & $0 \%$ & $0 \%$ & $12.75 \%$ \\
\hline
\end{tabular}

History of pain in abdomen was absent in $32(31.37 \%)$ cases, may be due to undisturbed nature of pregnancy or due to individual differences in the pain threshold. The incidence is comparable to above mentioned studies
(Table 10). They reported absence of amenorrhoea in $24.3 \%, 25 \%$ and $22.6 \%$ of cases as against $45.1 \%$ in the present series; this can be attributed to the early presentation of the patients to the clinic with symptoms. 
Vaginal bleeding of variable pattern was present in $31.37 \%$ cases. Amount of bleeding was scanty to moderate in most of the cases. Other authors elicited similar findings (Table 10). Other symptoms were giddiness, nausea, vomiting and syncopal attacks noted in $13(12.75 \%)$ cases in present study.

\section{Condition of the fallopian tube}

In the present study ruptured tubal pregnancy was the most common finding $(63.92 \%)$, which is in concordance with the findings of Shraddha Shetty et al. ${ }^{5}$ Tubal abortion noted by Gaddagi $\mathrm{R}$ et al and Shraddha Shetty et al in their study were $10.8 \%$ and $12.9 \%$ respectively, which is similar to the findings in the present study. ${ }^{5,10}$ Ruptured tubal ectopic pregnancy was the most common finding in the patients who presented with shock in the present study as well as in the studies by other authors.

\section{Site}

Ampulla was the most common site, noted in 64 cases in the present study. Same was noted by Rashmi Gaddagi et al and Lawani et al in their respective studies. ${ }^{10,12} 3$ cases of ectopic pregnancy in the rudimentary horn of bicornuate uterus was noted in the present study, which was similar to the finding of Rashmi Gaddagi et al. ${ }^{10} 2$ cases of heterotropic pregnancy were noted in the present study with ectopic pregnancy in fallopian tube.

\section{Side of the tube}

In the present study right sided fallopian tube was more commonly involved as compared to the left tube. Similar findings were noted by Laxmi RC et al and Shraddha Shetty et al in their respective studies. ${ }^{3,5}$ Preponderance of right side fallopian tube for ectopic pregnancy has been attributed to appendicitis.

\section{CONCLUSION}

The incidence of ectopic pregnancies is on rise as evident in this study. In order to reduce the morbidity and mortality due to ectopic pregnancies, there is need for early diagnosis especially in high risk cases. Ectopic pregnancy should be suspected in a woman of reproductive age presenting with the triad of pain in abdomen, amenorrhoea and vaginal bleed irrespective of the status of tubal ligation. Heterotropic pregnancy should be excluded in all the cases of ectopic pregnancy as early intervention is mandatory to salvage intrauterine pregnancy.
Funding: No funding sources Conflict of interest: None declared

Ethical approval: The study was approved by the Institutional Ethics Committee

\section{REFERENCES}

1. Ectopic pregnancy. In: Cunningham FG, Leveno KJ, Bloom SL, Spong CY, Dashe JS, Hoffman BL, et al., eds. Williams Obstetrics. 24th ed. New York: McGraw Hill; 2014:377-95.

2. ICMR- task free project- Multicentric case control study of ectopic pregnancy in India. J Obstet Gynaecol India. 1990;40:425-30.

3. Laxmi RC, Pradhan B, Duwa S. Annual analysis of ectopic pregnancy in tertiary care hospital. PMJN. 2011;11(1):5-8.

4. Baria DD, Thaker RV, Patel MS, Shah SR, Shah PT, Jani SK. Analysis of ectopic pregnancy at a tertiary care hospital: one year study. Int J Reprod Contracept Obstet Gynecol. 2013;2(4):621-5.

5. Shetty SK, Shetty AK. A clinical study of ectopic pregnancies in a tertiary care hospital of Mangalore, India. IJMHS. 2014;4(1):305-9.

6. Gupta R, Porwal S, Swarnkar M, Sharma N, Maheshwari P. Incidence, trends and risk factors for ectopic pregnancies in a tertiary care hospital of Rajasthan. JPBMS. 2012;16(07):1-3.

7. Shivakumar HC, Umashankar KM, Ramaraju HE. Analysis of forty cases of ectopic pregnancies in tertiary care hospital in south India. IJBAMR. 2013;3(1): 235-41.

8. Singh S, Mahendra G, Vijayalakshmi S, Pukale RS. Clinical study of ectopic pregnancy in a rural setup: a two year survey. Nat J Med Res. 2014;4(1):37-9.

9. Panchal D, Vaishnav G, Solanki K. Study of management in patient with ectopic pregnancy. NJIRM. 2011; 2(3):91-3.

10. Gaddagi RA, Chandrashekhar AP. A clinical study of ectopic pregnancy. JCDR. 2012;6(5): 867-9.

11. Shabab U, Hashmi HA. Different pattern of presentation of ectopic pregnancy and its management. J Surg Pak (International). 2013;18(1):37-40.

12. Lawani LO, Anozie OB, Ezeonu PO. Ectopic pregnancy: a life-threatening gynecological emergency. Int J Wom Health. 2013;5:515-21.

Cite this article as: Shukla DB, Jagtap SV, Kale PP, Thakkar HN. Study of ectopic pregnancy in a tertiary care centre. Int J Reprod Contracept Obstet Gynecol 2017;6:975-9. 